\title{
Identification of the $\mathrm{Bcl}-2$ and Bax homologs from Rhipicephalus haemaphysaloides and their function in the degeneration of tick salivary glands
}

Shanming $\mathrm{Hu}^{\dagger}$, Yanan Wang ${ }^{\dagger}$, Zhengmao Xu, Yongzhi Zhou, Jie Cao, Houshuang Zhang and Jinlin Zhou* ${ }^{*}$

\begin{abstract}
Background: The salivary glands of female ticks degenerate rapidly by apoptosis and autophagy after feeding. Bcl-2 family proteins play an important role in the apoptosis pathways, but the functions of these proteins in ticks are unclear. We studied Bcl-2 and Bax homologs from Rhipicephalus haemaphysaloides and determined their functions in the degeneration of the salivary glands.

Methods: Two molecules containing conserved $\mathrm{BH}$ (Bcl-2 family homology) domains were identified and named $R h B C l-2$ and RhBax. After protein purification and mouse immunization, specific polyclonal antibodies (PcAb) were created in response to the recombinant proteins. Reverse transcription quantitative PCR (RT-qPCR) and western blot were used to detect the presence of $R h B C l-2$ and RhBax in ticks. TUNEL assays were used to determine the level of apoptosis in the salivary glands of female ticks at different feeding times after gene silencing. Co-transfection and GST pull-down assays were used to identify interactions between RhBCl-2 and RhBax.

Results: The RT-qPCR assay revealed that RhBax gene transcription increased significantly during feeding at all tick developmental stages (engorged larvae, nymphs, and adult females). Transcriptional levels of RhBCl-2 and RhBax increased more significantly in the female salivary glands than in other tissues post engorgement. RhBCl-2 silencing significantly inhibited tick feeding. In contrast, RhBax interference had no effect on tick feeding. TUNEL staining showed that apoptosis levels were significantly reduced after interference with $R h B C l-2$ expression. Co-transfection and GST pull-down assays showed that RhBCl-2 and RhBax could interact but not combine in the absence of the BH3 domain.
\end{abstract}

Conclusions: This study identified the roles of $R h B C l-2$ and $R h B a x$ in tick salivary gland degeneration and finds that the $\mathrm{BH} 3$ domain is a key factor in their interactions.

Keywords: Salivary gland degeneration, Apoptosis, Bcl-2, Bax

*Correspondence: jinlinzhou@shvri.ac.cn

†Shanming Hu and Yanan Wang contributed equally to this work

Key Laboratory of Animal Parasitology of Ministry of Agriculture, Shanghai Veterinary Research Institute, Chinese Academy of Agricultural Sciences,

Shanghai 200241, China

\section{Background}

Ticks are obligate blood-feeding arthropods and vectors of many pathogens [1]. They usually stay attached to their hosts and feed for several days or even weeks [2]. The salivary glands of ticks mediate diverse functions that ensure tick survival [3]. Tick-borne pathogens (TBP) original author(s) and the source, provide a link to the Creative Commons licence, and indicate if changes were made. The images or other third party material in this article are included in the article's Creative Commons licence, unless indicated otherwise in a credit line to the material. If material is not included in the article's Creative Commons licence and your intended use is not permitted by statutory regulation or exceeds the permitted use, you will need to obtain permission directly from the copyright holder. To view a copy of this licence, visit http://creativecommons.org/licenses/by/4.0/. The Creative Commons Public Domain Dedication waiver (http://creativeco mmons.org/publicdomain/zero/1.0/) applies to the data made available in this article, unless otherwise stated in a credit line to the data. 
are transmitted to the host by the saliva used during tick feeding [4].

The salivary glands of female ticks degenerate rapidly within 4 days after engorgement [5]. Salivary gland degeneration begins at the early stage of rapid feeding and may be caused by apoptosis and autophagy related to the increase of ecdysone in the hemolymph [6, 7]. During degeneration, the granular acini undergo DNA fragmentation and caspase enzyme activity increases [8,9]. According to the comprehensive analysis of the global protein changes, some proteins associated with apoptosis and autophagy changed and some proteins linked to the degradation of DNA and proteins were consistently upregulated [10]. However, the mechanism of these effects is unknown.

Apoptosis is an important part of programmed cell death (PCD). Apoptosis is programmed to transmit death induction signals and carry out the biochemical processes of cell decomposition by a group of specific interacting proteins [11]. For embryonic development, tissue homeostasis, and organism stability in multicellular organisms, apoptosis is indispensable and is a normal physiological process [12]. During apoptosis, a decrease in cell volume, cytoplasmic condensation, mitochondrial membrane permeabilization, DNA fragmentation, and chromatin condensation followed by nuclear fragmentation and cytoplasmic membrane blebbing take place, which leads to complete cell division. In the late stage of apoptosis, apoptotic bodies are produced due to cell fragmentation [13].

Apoptosis is caused by sequential activation of cysteine proteases of the caspase family in two distinct but convergent pathways [14]. The extrinsic pathway, also known as the death receptor pathway, activates caspase- 8 when the "death receptor" Fas binds to its ligand FasL, and then recruits Fas-associated death domain (FADD) proteins and caspase- 8 enzymes in the cytoplasm to form a deathinducing signaling complex (DISC) [15]. The intrinsic pathway (also termed the mitochondrial pathway) can be triggered by the proapoptotic proteins of the B-cell lymphoma 2 (Bcl-2) family. These cause mitochondrial membrane permeabilization to release mitochondrial cytochrome $c$ into the cytoplasm, further activating caspases to induce apoptosis [16]. These initiator caspases can cleave and activate the effector caspases (caspase-3, caspase-6, and caspase-7) that mediate cellular demolition by cleaving multiple critical cellular proteins [17].

The $\mathrm{Bcl}-2$ protein family is involved in apoptosis via the intrinsic pathway. $\mathrm{Bcl}-2$ was first discovered via a chromosome translocation that is the hallmark of human follicular lymphoma, and it was subsequently found to promote cell survival as an antiapoptotic protein of the Bcl-2 protein family [18]. Its homologs Bcl-X, Bcl-w,
Mcl-1, and A1 were also found to inhibit apoptosis, but $\mathrm{Bax}, \mathrm{Bak}$, and Bok promoted apoptosis. The Bcl-2 homology $(\mathrm{BH})$ domain is a vital functional domain for the interaction of the Bcl-2 family proteins. The $\mathrm{BH} 3$ domain was found to be a key domain for Bax, Bak, and Bok to promote apoptosis [19]. Bim, Bid, Bad, Puma, and Noxa only had the $\mathrm{BH} 3$ domain, so they were termed $\mathrm{BH} 3$-only proteins.

The $\mathrm{Bcl}-2$ family proteins regulate apoptosis mainly by regulating mitochondrial membrane permeability, either alone or in collaboration with other proteins. For example, Bax forms oligomers on the mitochondrial membrane that perturb membrane integrity and promote apoptosis, while Bcl-2 and Bcl-xL inhibit their effects by binding to Bax to form heterodimers [20, 21]. BH3-only protein can play a direct or indirect proapoptotic role. It can directly bind and activate Bax and Bak proteins to promote apoptosis, and it can also indirectly promote Bax and Bak protein expression to cause apoptosis by inhibiting the action of the anti-proteins [22, 23].

$\mathrm{Bcl}-2$ family proteins exist in both mammalian and non-mammalian species. The nematode Caenorhabditis elegans has two members of the Bcl-2 family, EGL-1 and CED-9, that regulate cell death [24]. Two Bcl-2 family proteins (Debcl and Buffy) have high homology with Bok found in Drosophila [6]. Using RNA interference, Ayllon [25] injected Bcl-2 dsRNA into Ixodes scapularis and showed feeding disruption. This indicated that Bcl-2 plays an important role in the intrinsic apoptosis of ticks. However, the mechanism by which Bcl-2 family proteins regulate apoptosis in ticks is unknown. In this study, we identified Bcl-2 and Bax from Rhipicephalus haemaphysaloides and investigated their functions in the degeneration of tick salivary glands at different feeding times.

\section{Methods}

\section{Tick feeding and tissue collection}

Adult $R$. haemaphysaloides were collected from water baffles in May 2001 in Wuhan, Hubei Province, China. The ticks were fed on the ears of New Zealand white rabbits (SLAC, Shanghai Institutes for Biological Science, CAS), and maintained in artificial climate incubators of the Shanghai Veterinary Research Institute [26]. Tick tissues were rapidly dissected, washed with phosphate-buffered saline (PBS, PH 7.4, with $0.14 \mathrm{M} \mathrm{NaCl}$ and $0.0027 \mathrm{M}$ $\mathrm{KCl}, 0.01 \mathrm{M}$ phosphate buffer; Gibco, Life Technologies, Carlsbad, CA, USA), and placed in PBS or TRIzol (Invitrogen, Carlsbad, CA, USA) reagent at $-80{ }^{\circ} \mathrm{C}$.

\section{RNA extraction and CDNA synthesis}

RNA was derived from ticks dissected at different development stages (eggs, unfed and fed larvae, nymphs, and adults) and different tissues (salivary glands, midguts, 
and ovaries of female ticks), and preserved in TRIzol reagent. The HiScript ${ }^{\circledR}$ III RT SuperMix for qPCR (+gDNA wiper) kit (Vazyme Biotech, Nanjing, China) was used, according to manufacturer protocol.

\section{Cloning, sequence analysis}

RhBcl-2 and RhBax primers were designed based on a comparison of the salivary gland transcriptomes of starved and engorged $R$. haemaphysaloides [27, 28]. A BLAST analysis of the translation products deduced from the open reading frames (ORFs) was performed. SignalP 4.1 (http://www.cbs.dtu.dk/services/SignalP/) [29] and ExPASy (http://web.expasy.org/compute_pi/) [30] were used for the signal peptide analysis and isoelectric point (pI) prediction. We aligned $R h B c l-2$ and $R h B a x$ with the Bcl-2 and Bax protein sequences of other species using Genetyx v.6 (GENETYX, Tokyo, Japan). For phylogenetic analysis, the alignment of the sequences was performed using the MUSCLE algorithm [31] and inferred using the maximum likelihood method with the default settings in MEGA X software [32]. Bootstrap support values were estimated using 500 bootstrap replicates [28].

\section{RT-qPCR analyses}

The expression levels of $R h B c l-2$ and $R h B a x$ were examined in different development stages (eggs, unfed and fed larvae, nymphs, and adults) and different tissues (salivary glands, midguts, and ovaries of female ticks) during the feeding time. The feeding time includes the early-feeding period (fed 3 days), the fast-feeding period (fed 5 to 7 days), and the end of the feeding period (engorged 1 to 3 days) [28]. After $R h B c l-2$ and RhBax primers (Additional file 1: Table S1) designed using Primer Premier 5, the cDNAs of the above stages and tissues were analyzed by RT-qPCRs, which were conducted using ChamQ Universal SYBR qPCR Master Mix (Vazyme) green and gene-specific (Additional file 1: Table S1) primers with a QuantStudio 5 PCR System (Applied Biosystems, Austin, TX, USA). The RT-qPCR process consisted of $95{ }^{\circ} \mathrm{C}$ for $30 \mathrm{~s}$, then 40 cycles of $95{ }^{\circ} \mathrm{C}$ for $5 \mathrm{~s}$ and $60{ }^{\circ} \mathrm{C}$ for $30 \mathrm{~s}$, followed by analysis of the melting curve. All samples were analyzed in triplicate. The data used elongation factor-1 (ELF1A, GenBank Accession number AB836665) as an internal control [31], and this was used to analyze the relative gene expression in each sample by the $2^{-\triangle \mathrm{Ct}}$ method [32, 33].

\section{Expression of recombinant $R h B C l-2$ and $R h B a x$}

Specific $R h B c l-2$ and $R h B a x$ primers (Additional file 1: Table S2) were designed in a pET-30a or PGEX-4T-1 vector. The $R h B c l-2$ and $R h B a x$ amplified PCR products were purified and digested with $B a m H I, E c o R I$, or XhoI (New England Biolabs, USA) and ligated into pET-28a or
PGEX-4T-1 (Invitrogen) using the In-Fusion HD Cloning Kit (Takara Clontech, Mountain View, CA, USA) [28]. These recombinants were transformed and expressed in Escherichia coli BL21 (DE3) strain (TIANGEN, Beijing, China). The strains were grown at $37{ }^{\circ} \mathrm{C}$ until the $\mathrm{OD}_{600}$ reached 0.8 . After isopropyl $\beta$-D-1-thiogalactopyranoside (IPTG) was added to $1 \mathrm{mM}$, the protein expression was induced at $25^{\circ} \mathrm{C}$ for $20 \mathrm{~h}$. The recombinant, containing His-tagged protein, was purified by affinity chromatography using Ni-NTA His resin (Thermo Fisher Scientific, Waltham, MA, USA). The recombinant containing the glutathione-S-transferase (GST)-tagged protein was purified by affinity chromatography using resin and gravity.

\section{GST pull-down of RhBcl-2 and RhBax}

To confirm whether RhBcl-2 interacts with RhBax, $1 \mathrm{mM}$ IPTG induced expression for $8 \mathrm{~h}$ of pET-30a-RhBax, PGEX-4T-RhBcl-2, and PGEX-4T-1 recombinant E. coli BL21. The supernatant was separated using GST agarose (Merck, Darmstadt, Germany) according to manufacturer's instructions. Anti-GST antibody (Proteintech, Chicago, IL, USA) and goat anti-mouse secondary antibody (Proteintech) were used to confirm that GST/ GST-RhBcl-2 was successfully separated, and anti-His antibody (Proteintech) was used to detect the His-RhBax protein.

\section{Cells and transient co-transfection assays}

HEK 293T cells were maintained in Dulbecco's modified Eagle medium (DMEM, Gibco), supplemented with 8\% heat-inactivated fetal bovine serum (Biological Industries, Kibbutz Beit Haemek, Israel) and $1 \%$ penicillin (Gibco) at $37^{\circ} \mathrm{C}[28]$.

The full-length ORF of $\mathrm{RhBcl}-2$ was inserted into the p3 $\times$ Flag-CMV-14 vector (MiaoLing Plasmid Sharing Platform, Wuhan, China) with FLAG-tag at the N-terminal with gene-specific primers (Additional file 1: Table S2). RhBax was inserted into the pCMV-HA vector using the same method. The fragment of RhBax deleted BH3 domain (RhBax- $\mathrm{BH} 3)$ and $\mathrm{BH} 1$ domain $($ RhBax- $\triangle \mathrm{BH} 1)$ was amplified by splicing by overlap extension (SOE) of recombinant PCR with specific primers (Additional file 1: Table S3), and they were inserted into the pCMV-HA vector [34]. Transfection using Lipofectamine $^{\mathrm{TM}} 3000$ Transfection Reagent (Invitrogen) was performed according to the manufacturer's protocol with a DNA-to-lipofectamine ratio of $1: 2 \mathrm{w} / \mathrm{v}$. The HEK 293T cells were transformed with $2.5 \mu \mathrm{g} /$ well of plasmid or co-transfected with the equivalent amount of two different plasmids in six-well plates [28]. After $24 \mathrm{~h}$, cells were washed twice with cold PBS. They were then lysed in a modified RIPA buffer (Thermo Fisher Scientific, 
Waltham, MA, USA) in the presence of phenylmethylsulfonyl fluoride (PMSF) (Sangon Biotech Co., Ltd., Shanghai, China), after which they were then placed on ice for 10 min on a swirling plate to ensure uniform spreading. The samples were then centrifuged at $12,000 \times g$ for 10 min to pellet the cell debris.

\section{Antibody generation}

We predicted the epitopes of RhBcl-2 and RhBax online (http://www.iedb.org/), and synthesized keyhole limpet hemocyanin (KLH) [35]-coupled polypeptides based on the epitope amino acid sequences (RhBcl-2: GLQWNTCPPLPRPSK, RhBax: STPTHEETREE). Polypeptides were dissolved in PBS and Freund's adjuvant (complete and incomplete; Invitrogen). Equal volumes of these solutions were then emulsified together and intraperitoneally injected into 6- to 8-week-old BALC/c mice provided by the Shanghai Laboratory Animal Center (Shanghai Institutes for Biological Science, Chinese Academy of Sciences, Shanghai, China). The mixtures were injected three times at 2-week intervals. Serum was collected from the posterior orbital vein on the seventh day after the third immunization. RhBcl-2 and RhBax anti-sera were used to detect $\mathrm{RhBcl}-2$ and $\mathrm{RhBax}$ in protein extracts.

\section{Western blotting}

The collected ticks and tick tissues were extracted using Tris-buffered saline (TBS; $10 \mathrm{mM}$ Tris- $\mathrm{HCl}, \mathrm{pH}$ 7.5; $150 \mathrm{mM} \mathrm{NaCl}$ with $1 \mathrm{mM}$ phenylmethanesulfonyl fluoride) in the presence of phenylmethylsulfonyl fluoride (PMSF) (Sangon Biotech Co., Ltd., Shanghai, China). These samples were then placed on ice and broken by sonication. A Bradford Protein Assay Kit (TIANGEN) was used to determine the protein concentration. Proteins were separated by $10 \%$ sodium dodecyl sulphate polyacrylamide gel electrophoresis (SDS-PAGE, 12\%, Genescript, Nanjing, China) and transferred onto polyvinylidene difluoride (PVDF) membranes. After blocking in TBS containing 5\% skim milk, the proteins were incubated at $4{ }^{\circ} \mathrm{C}$ overnight with primary antibodies (FLAG Tag D6W5B, Cell Signaling Technology Inc., Danvers, MA, USA; HA-Tag C29F4, Cell Signaling Technology Inc.; GST Tag, 66001-2-Ig, Proteintech, Chicago, IL, USA; His Tag, 66005-1-Ig, Proteintech). Anti RhBcl-2 and RhBax sera were used to detect RhBcl-2 and RhBax in protein extracts, and anti-tubulin (66031-1-Ig, Proteintech) primary antibody was used as a constitutive control to normalize the signal from the target protein. The membranes were rinsed five times in Tris-buffered saline with Tween-20 (TBST) and incubated with a secondary antibody IgG(H+L) conjugated with HRP (goat anti-mouse, 31430, 1:5000, Thermo Fisher Scientific; goat anti-rabbit, 31460, 1:5000, Thermo Fisher Scientific) for $1 \mathrm{~h}$ at room temperature. The membranes were rinsed five times with TBST. The signal was detected with an Enhanced Chemiluminescent Substrate Reagent Kit (NCM Biotech, Suzhou, China). Images were captured using the ChemiDoc Touch imaging system (Bio-Rad, Hercules, CA, USA) [28].

\section{RNAi of RhBCl-2 or RhBax}

The RNAi experiments were designed against $R h B c l$ 2 and $R h B a x$ genes. For the design of RNAi primers, RhBcl-2 and RhBax sequences were screened by Primer Premier 5. Specific primers (Additional file 1: Table S4) containing the T7 polymerase promoter sequence were used for PCR amplification. The amplicons were then purified to obtain templates for double-stranded RNA synthesis using the T7 RiboMAX Express RNAi system (Promega, Madison, WI, USA). The unrelated gene Luciferase dsRNA was synthesized using the same methods described previously and used as the negative control. Unfed female ticks ( $n=20$ females per group) were microinjected with approximately $1 \mu \mathrm{g}$ of dsRNA. Control ticks were injected with unrelated Luciferase dsRNA. After dsRNA injection, ticks were held in a humidity chamber for 1 day, after which they were allowed to feed on rabbit ears until they were fully engorged. Each group (control and $R h B c l-2$ or $R h B a x$ ) of ticks was allowed to feed on three rabbits ( 20 ticks on each rabbit). The biological parameters analyzed were: attachment rate at $24 \mathrm{~h}$ (counting the number of dead females attached to rabbit ears on the next day); number of engorged ticks (counting the number of females dropped off rabbit ears on the seventh day); death rate (counting the number of dead females on the seventh day); egg laying rate (counting how many females had the ability to lay eggs on the 15th day), and hatchability rate (counting how many egg larvae hatched on the 13th day). RT-qPCR was used to evaluate gene silencing efficiency.

Interference with the salivary glands was performed using dsRNA in vitro. The salivary glands of female ticks fed on rabbit for 5 days were dissected and placed into complete L15 medium with $1 \%$ penicillin-streptomycin [36]. Each well received $5 \mu \mathrm{g}$ of dsRNA and was incubated at $27{ }^{\circ} \mathrm{C}$ with no $\mathrm{CO}_{2}$ for $48 \mathrm{~h}$. The control group received unrelated Luciferase dsRNA. Each treatment group included the salivary glands from 10 ticks. After incubation, the dissected salivary glands in each group were fixed in $4 \%$ paraformaldehyde for TUNEL staining or fixed in $2.5 \%$ glutaraldehyde at $4{ }^{\circ} \mathrm{C}$ for at least $24 \mathrm{~h}$. The remaining salivary glands were used for western blot and RNA.

The data were obtained from three independent experiments with three biological replicates, and were used to 
analyze the relative gene expression in each sample by the $2^{-\Delta \mathrm{Ct}}$ method.

\section{TUNEL staining}

Salivary glands were fixed in $4 \%$ paraformaldehyde and embedded in paraffin. Sections $(5 \mu \mathrm{m})$ of salivary glands were mounted on microscope slides. Sections were then deparaffinized, washed in 100\% ethanol, and rehydrated. Samples were washed with PBS. After antigen retrieval with $0.1 \%$ Triton $\mathrm{X}-100$, the sections were incubated for $1 \mathrm{~h}$ with 1:9 TdT mixed with fluorescent-labeled dUTP at $37{ }^{\circ} \mathrm{C}$, following the instructions of the Roche In Situ Cell Death Detection Kit, POD (Roche, Mannheim, Germany). After washing 2-3 times with PBS, the sections

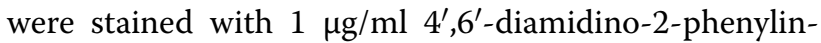
dole (DAPI, Invitrogen) in distilled water for $20 \mathrm{~min}$ [28]. After washing, the sections were mounted using Lab Vision ${ }^{\mathrm{TM}}$ PermaFluor $^{\mathrm{TM}}$ (Invitrogen) medium under glass coverslips, then viewed and photographed in a
Pannoramic DESK Digital Slide Scanner (3D HISTECH, Budapest, Hungary) [28]. The TUNEL mean fluorescence intensity was measured using Image-Pro Plus software (IPP, Maryland, USA).

\section{Data analysis}

All statistical analyses were performed using GraphPad Prism 6.0 software (GraphPad Software Inc., San Diego, $\mathrm{CA}, \mathrm{USA})$. Mean \pm standard error (SEM) values were calculated for three separate experiments, and two-tailed Student's $t$ tests were used to identify significant differences between groups. A value of $P<0.05$ was considered to be statistically significant.

\section{Results}

\section{Sequence analysis of $R h B C l-2$ and $R h B a x$}

We used nucleic acid sequences obtained from RNAseq. Specific cloning primers were designed according to the predicted sequences of $R$. haemaphysaloides $\mathrm{Bcl}-2$ and

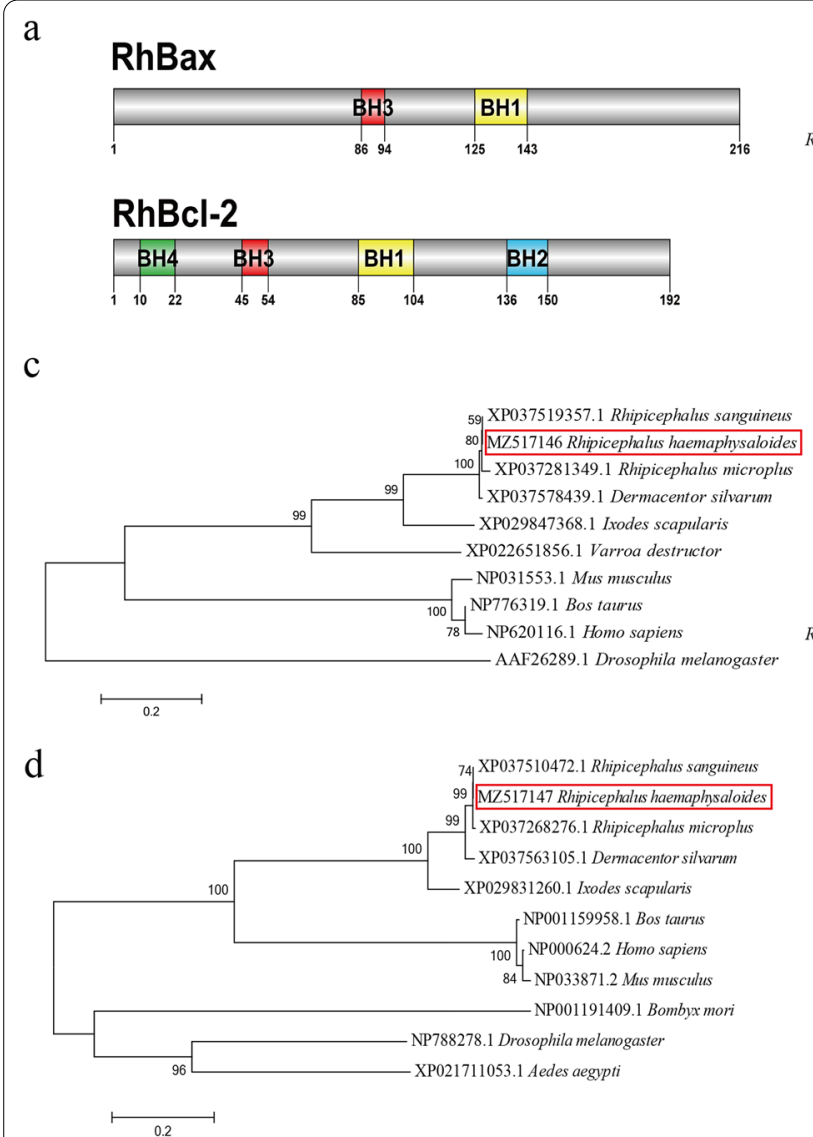

\section{b RhBax}

Homo sapiens 1:MDGSGEQPRGGGPTSSEQIMKTGALLLQGFIQD---RAGR-MGGEAPELALDP--VPQDA 54 Mus musculus 1:MDGSGEQLGSGGPTSSEQIMKTGAFLLOGFIQD---RAGR-MAGETPELTLEQ--PPQDA 54 Rhipicephalus microplus 1:MSIPLPLLRST-PTHEETREE-GRVLLSSFVDYQVAQEGAAMDAGASSESIGDMVYSHTI 58 $\star \ldots \ldots \ldots \ldots * \star \ldots \star \ldots \ldots * . \star \star ., \ldots \quad \ldots *$. $\ldots \ldots \ldots . \quad \ldots$ 55: STKKLS--------ECLKRIGDELDSNME-LQRMIAA------V--DTD--SP----REV 91
55: STKKLS-------ECLRRIGDELDSNME-LORMIAD-----V--DTD--SP----REV 91 59:DEEDIGTPHSRTEAEALHPVYRNMGRELRALADRFSQSRERIRVRQEADSLDLSSLTRDN 11

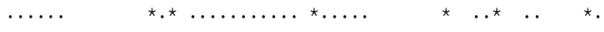

92: FFRVAADMFSDGNFNWGRVVALFYFASKLVLKAL-CTKVPELIRTIMGWTLDFLRERLLG 150 92: FFRVAADMFADGNFNWGRVVALFYFASKLVLKAL-CTKVPELIRTIMGWTLDFLRERLLV 150 119: LTTLMLELFEDG-FSRERLVTFFFFCSDLILKSVRCSVG-GLRWQVVAWVWAFLRDRVCC 17

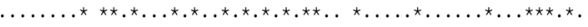

151:WIQDQGGWDGLLSY-FGTPTWQTVTIFVAGVLTASLTIWKKMG 151:WIQDQGGWEGLLSY-FGTPTWQTVTIFVAGVLTASLTIWKKMG 177:WVLQHGGWEAVLTNYLPKLAITAAG-FAVCVGVVFY-IWKNW-

$\mathrm{RhBcl}-2$

Homo sapiens 1: MAHAGRTGYDNREIVMKYIHYKLSORGYEWDAGDVGAAPPGAAPAPGIFSSQPGHTPHPA 60 Mus musculus 1 : MAQAGRTGYDNREIVMKYIHYKLSORGYEWDAGDADAAPLGAAPTPGIFSFQPESNPMPA 60 Rhipicephalus microphs 1: MAVNEAEKTQVNELVNDFMRYQLNRRGLQWN-----.-- 31

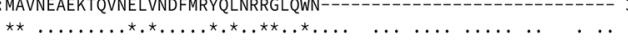
61: ASRDPVARTS-PLQTPAAPGAAAGPALSPVPPVVHLTLRQAGDDFSRRYRRDFAEMSSQL 119 61:VHRDMAARTS-PLRPLVATA---GPALSPVPPVVHLTLRRAGDDFSRRYRRDFAEMSSQL 116 $32:------T C P P L P R-----------P S K--V S L V L R T L G D E F V T K Y R E E F T Q M C G R L 68$

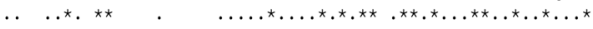

120: HLTPFTARGRFATVVEELFRDGVNWGRIVAFFEFGGVMCVESVNREMSPLVDNIALWMTE 179 117: HLTPFTARGRFATVVEELFRDGVNWGRIVAFFEFGGVMCVESVNREMSPLVDNIALWMTE 176 69: DMTPSVAQTAYTDVLNELFSEGITWARIVGAFAFSVELSALCVEKNWSELVDSIASWLSS 128

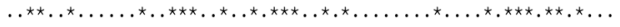

180:YLNRHLHTWIQDNGGWDAFVELYGPSMRPLFDF--SWLSLKTLLSL-ALVG-ACI-TLGA 234 177:YLNRHLHTWIQDNGGWDAFVELYGPSMRPLFDF--SWLSLKTLLSL-ALVG-ACI-TLGA 231 129:YVCTRLLPWIKDHQGWDGLVV-FSEERDDTGAAESPWPIFKNVVCGVA-VTALGALTLGA 186

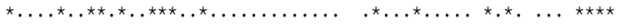

235:YLGHK-

232: YLGHK-

187: FLTSKS

Fig. 1 Sequence and structure analysis of Rhipicephalus haemaphysaloides $R h B C l-2$ and $R h B a x$. a Domain structure of $R h B C l-2$ and $R h B a x$. $\mathbf{b}$ Alignment of the deduced amino acid sequences of RhBCl-2 (MZ517147) and RhBax (MZ517147); Homo sapiens Bcl-2: NP_000648.2; Mus musculus Bcl-2: NP_803129.2; Homo sapiens Bax: NP_001278357.1; Mus musculus Bax: NP_031553.1; c Phylogenetic tree of RhBax with the Bax of other species. d Phylogenetic tree of $\mathrm{RhBCl}-2$ with the $\mathrm{BCl}-2$ of other species. Bootstrap values after 500 simulations are shown at the branches. RhBCl-2 and RhBax are marked with black triangle 
Bax (Additional file 1: Table S2). The ORF regions of $\mathrm{Bcl}-2$ and Bax genes were cloned from the cDNA of fully engorged $R$. haemaphysaloides female salivary glands and named $R h B c l-2$ and $R h B a x$. RhBcl-2 ORF has $576 \mathrm{bp}$ and encodes a protein of 192 amino acid residues with a deduced molecular weight (MW) and theoretical isoelectric point (PI) of $21.4 \mathrm{kDa}$ and 4.87 , respectively. RhBax ORF has $648 \mathrm{bp}$ and encodes a protein with 216 amino acid residues. It has a deduced MW of $24.6 \mathrm{kDa}$ and a PI of 5.28. RhBcl-2 had the conserved $\mathrm{BH} 1, \mathrm{BH} 2, \mathrm{BH} 3$, and $\mathrm{BH} 4$ domains, but RhBax had the conserved BH1 and BH3 domains (Fig. 1a).

The protein alignment and phylogenetic analyses showed the relationship between $R h B c l-2$ or RhBax and
Bcl-2 or Bax of other species (Fig. 1b-d). RhBcl-2 and RhBax are highly homologous to their homologs in other ticks. Moreover, their similarity with mammals (Homo sapiens, Mus musculus and Bos taurus) are higher than with insects (Drosophila melanogaster, Bombyx mori and Aedes aegypti).

Transcription and translation of $R h B C l-2$ and $R h B a x$ profiles in different tissues, feeding periods and development stages

The cDNA of eggs, larvae (unfed and engorged), and nymphs (unfed and engorged) were subjected to RTqPCR to evaluate the expression profiles of $R h B c l-2$ and RhBax genes (Fig. 2a). The cDNA of unfed adults

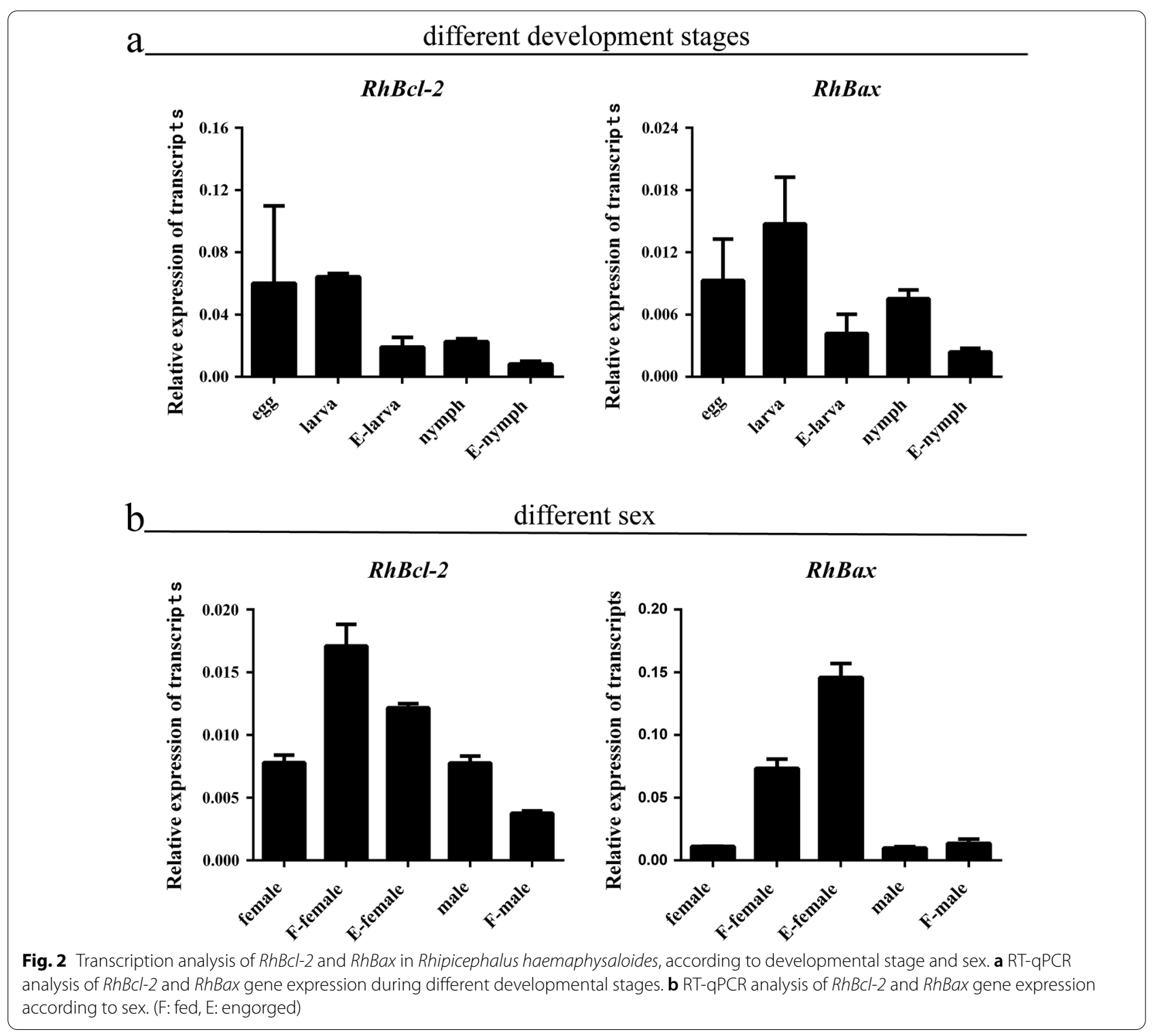



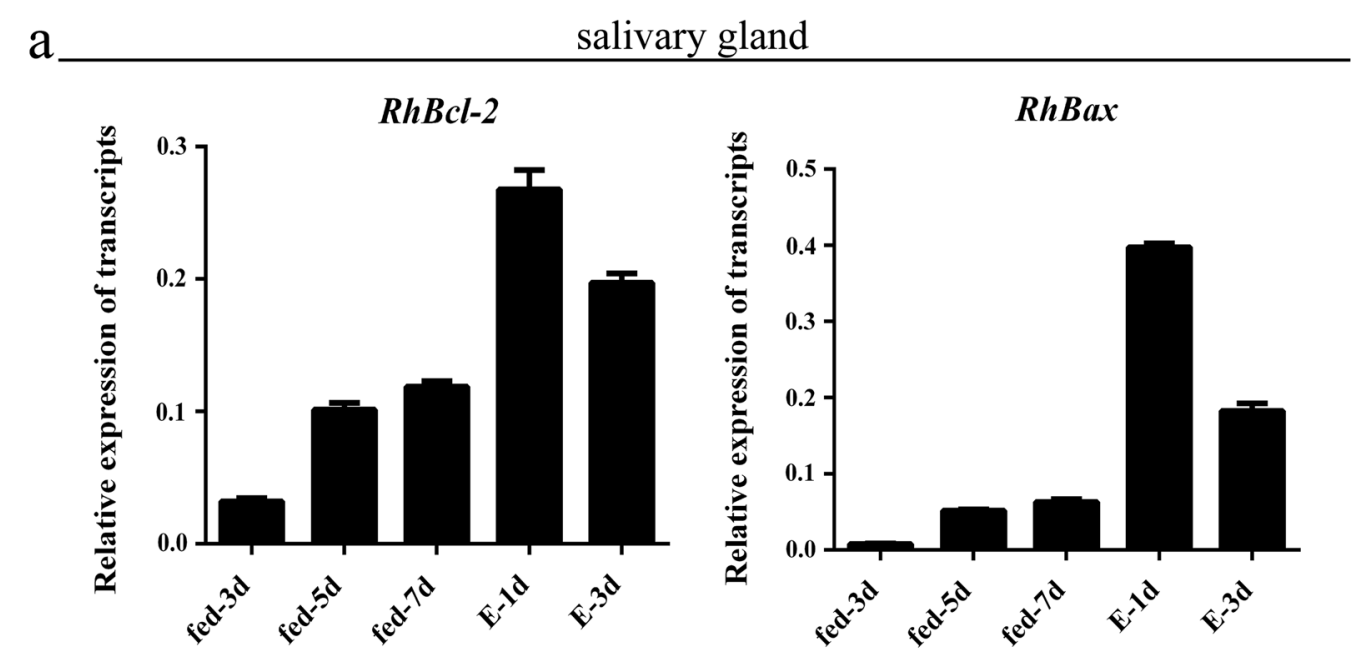

b midgut

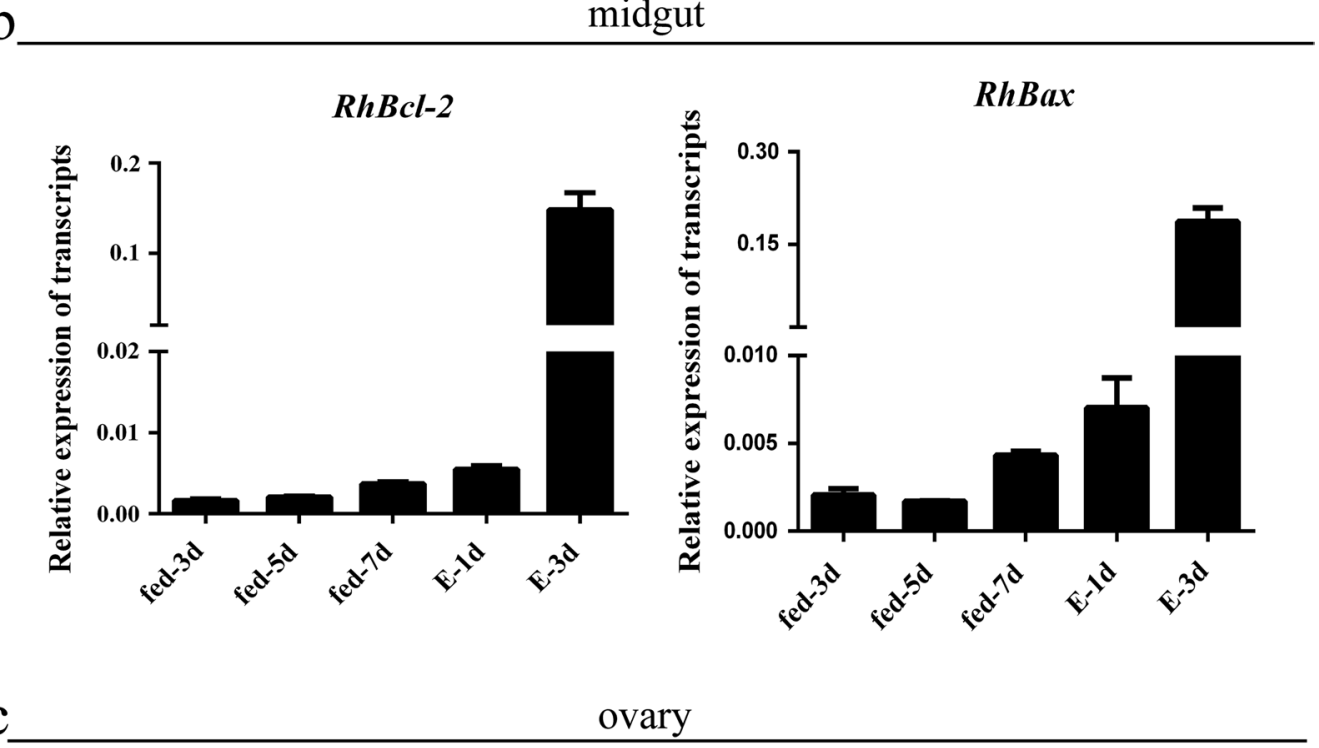

c

RhBcl-2

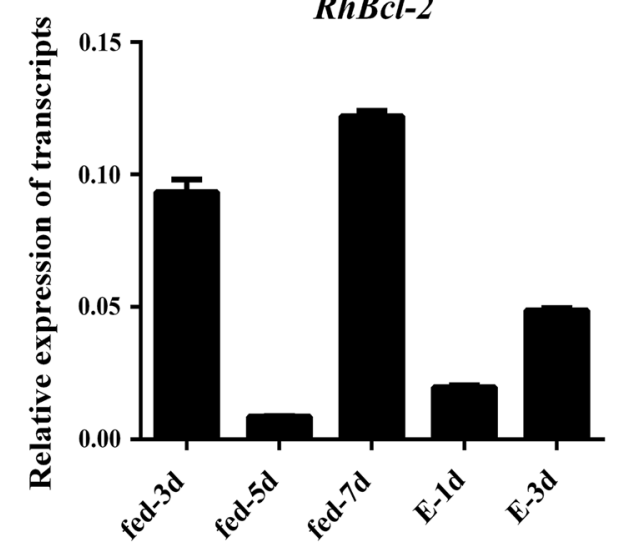

RhBax

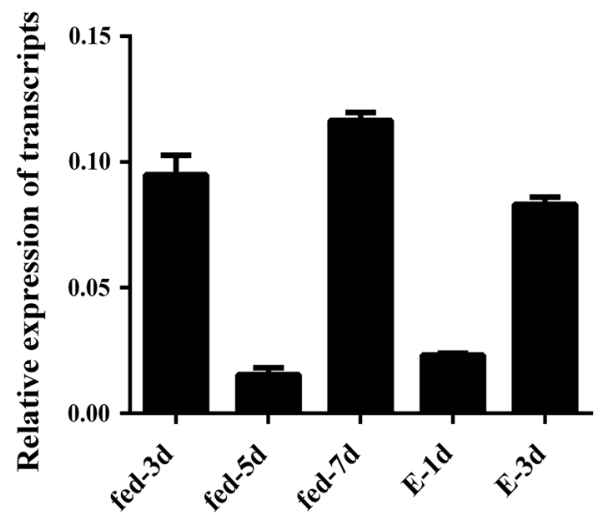

Fig. 3 Transcription analysis of $R h B C l-2$ and RhBax in Rhipicephalus haemaphysaloides in different tissues. a-c Transcription of $R h B C l-2$ and $R h B a x$ in different tissues of $R$. haemaphysaloides during feeding time. (E: engorged) 


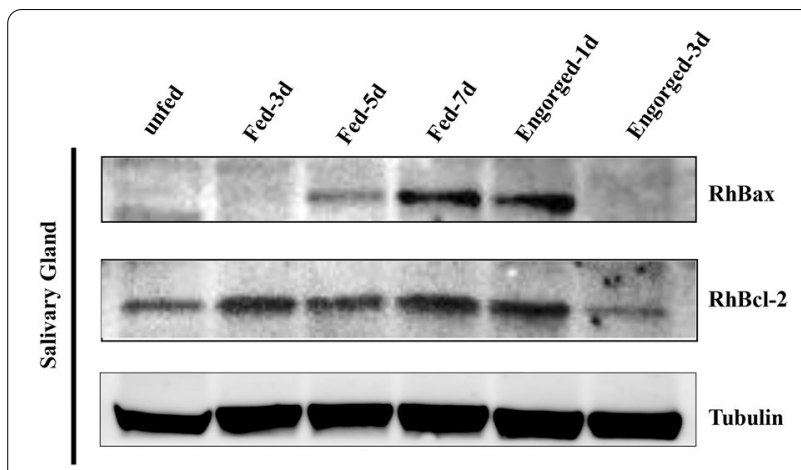

Fig. 4 Western blot detection of RhBCl-2 and RhBax in salivary glands from female Rhipicephalus haemaphysaloides at different feeding times. Tick salivary glands were screened with sera anti-RhBCl-2 and RhBax, and anti-tubulin serum was used as the control

(females and males), fed adults (females and males), and engorged female ticks were used to determine the sexspecific profile of $R h B c l-2$ and RhBax genes (Fig. 2b). The transcription level of $R h B a x$ increased during feeding in females.

After microdissection, the cDNAs of salivary glands, ovaries, and midguts of adult females at different feeding times were analyzed for $R h B c l-2$ and $R h B a x$ gene expression profiles (Fig. $3 \mathrm{a}-\mathrm{C}$ ). RhBcl-2 and RhBax genes were expressed in the examined tick tissues during feeding. However, RhBcl-2 and RhBax had the same expression trends in different organs.

Western blot analysis was performed using RhBcl-2 and RhBax anti-sera (Fig. 4). RhBax was detected during the fast-feeding period to post-engorgement, and RhBcl-2 was in the feeding stages.

\section{Expression of RhBcl-2 and RhBax}

The coding sequences of $R h B c l-2$ and $R h B a x$ were cloned into prokaryotic expression vectors (pET-28a and pGEX$4 \mathrm{~T}-1)$ to produce recombinant $\mathrm{RhBcl}-2$ and RhBax. All of the recombinant proteins were expressed as inclusion bodies in E. coli.

After solubilization and purification, His-RhBax (molecular weight: $\sim 38 \mathrm{kDa}$ ) and GST-RhBcl-2 (molecular weight: $\sim 50 \mathrm{kDa}$ ) were obtained, respectively (Fig. $5 \mathrm{a}$, b). Specific polyclonal antibodies (PcAb) were created in response to the recombinant protein. Western blot analysis revealed that the two sera were able to identify the full recombinant proteins (Fig. 5c, d), and the fragment sizes were consistent with those observed by SDS-PAGE.
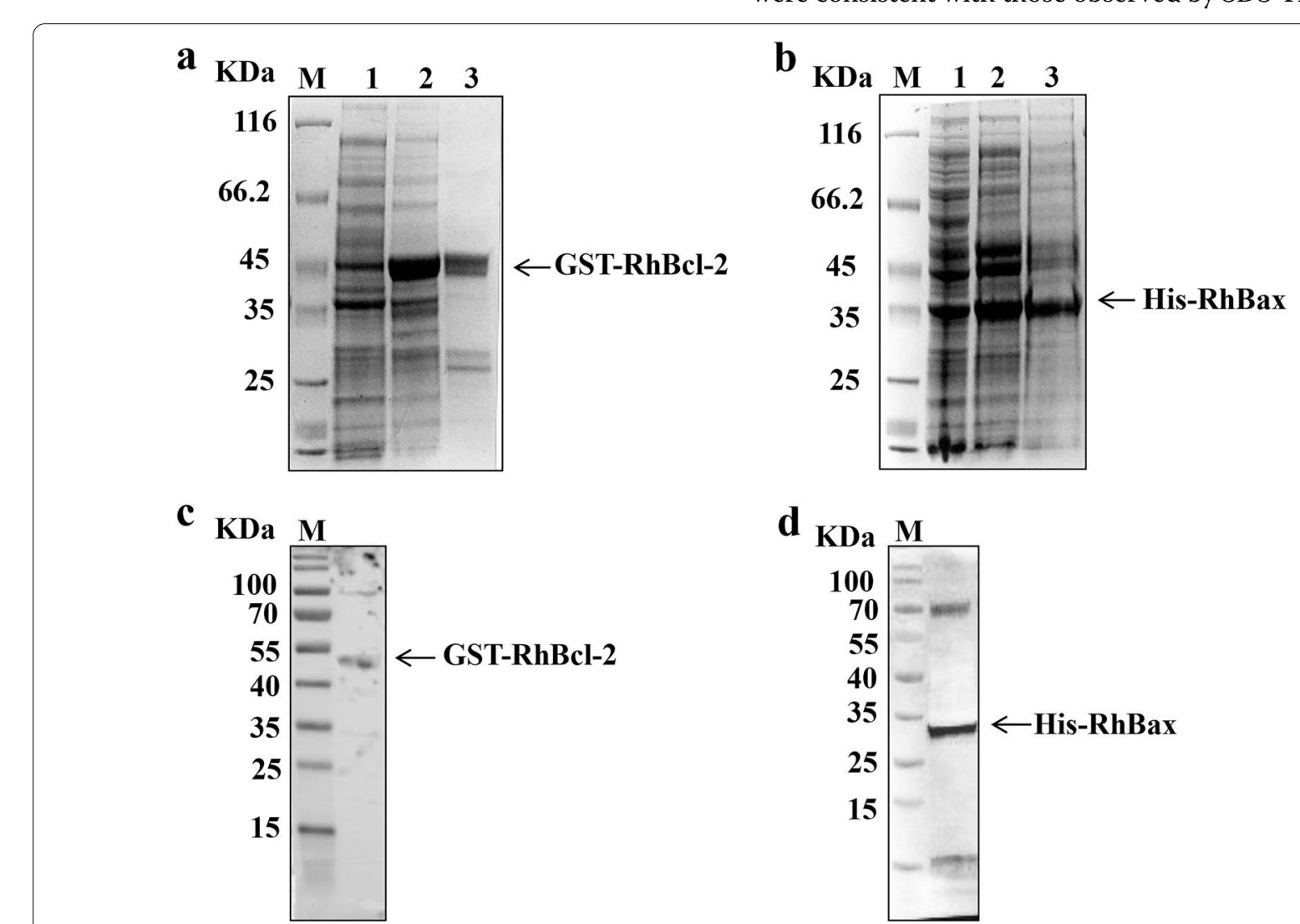

Fig. 5 Expression of recombinant RhBcl-2 and RhBax. a, b Purification of recombinant RhBcl-2 and RhBax. Lane 1: M: the protein marker; Lane 2: non-induced; Lane 3: 1 mM IPTG induced expression for 8 h; Lane 4: recombinant protein after purification. $\mathbf{c}$, $\mathbf{d}$ Western-blotting detection of RhBcl-2 and RhBax. Purified RhBcl-2 and RhBax were immunoblotted with the anti-sera against RhBCl-2 and RhBax, respectively 

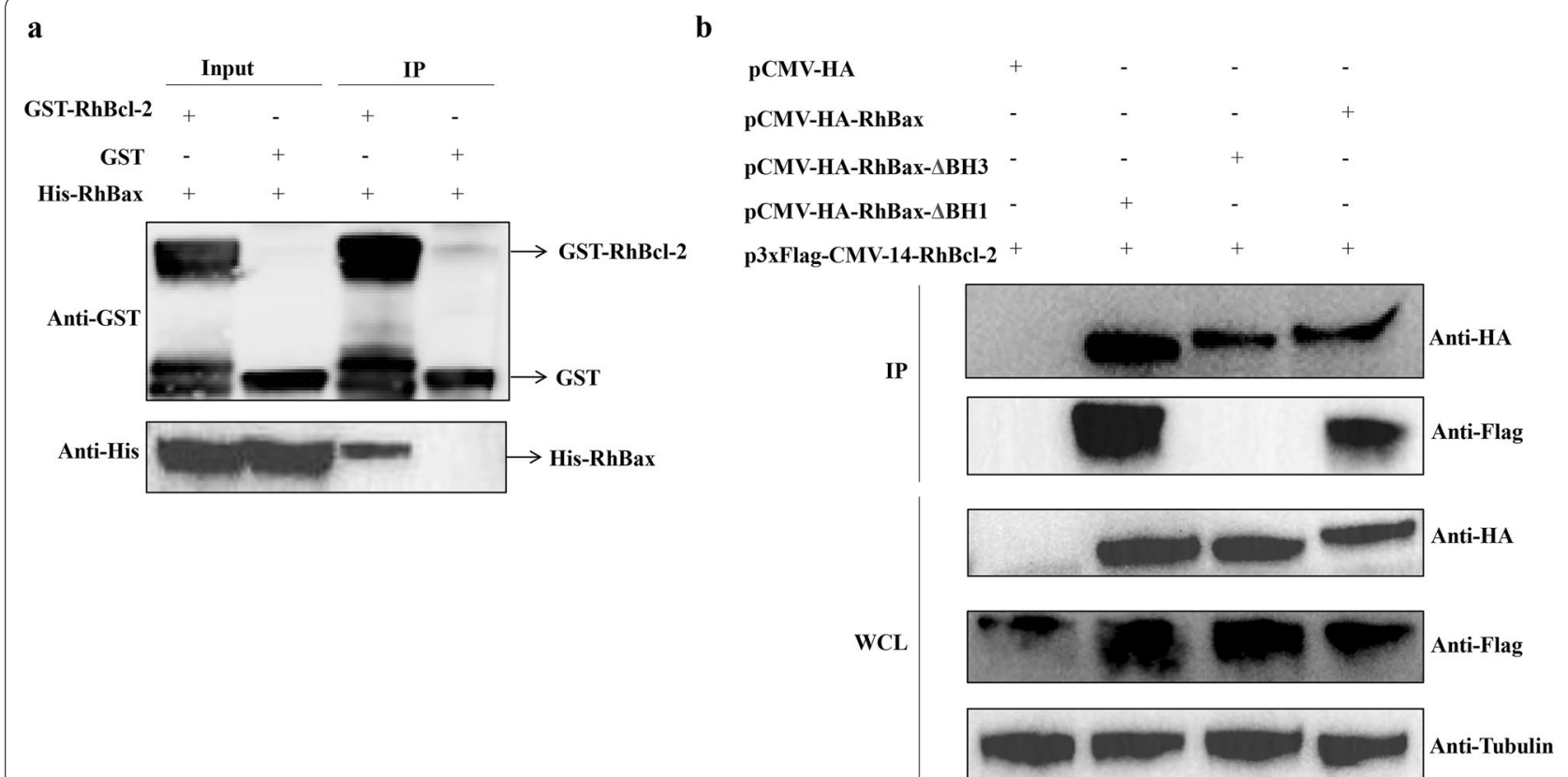

Fig. 6 GST pull-down binding and co-transfection assays of the RhBcl-2 and RhBax. a The input protein (IP) samples showed pull-down binding assays of His-RhBax as prey with RhBCl-2 as a bait. The IP shows pull-down binding assays of His-RhBax with the GST-RhBCl-2. GST is used as a negative control. $\mathbf{b}$ Western blotting analysis of the interaction between RhBcl-2 and RhBax by co-transfection into HEK-293T cells. Lane 1: Cells co-transfected p3 ×Flag-CMV-14-RhBCl-2 with pCMV-HA vector. Lanes 2-4: Cells co-transfected p3 × Flag-CMV-14-RhBCl-2 with pCMV-HA-RhBax- $\triangle \mathrm{BH} 1, \mathrm{pCMV}-\mathrm{HARhBax}-\triangle \mathrm{BH} 3$ and pCMV-HA-RhBax

RhBcl-2 binds with RhBax by BH3 domain

To verify that $\mathrm{RhBcl}-2$ interacts with $\mathrm{RhBax}$, an in-vitro GST pull-down assay was used to confirm the interaction between His-RhBax and GST-RhBcl-2 (Fig. 6a). For this experiment, two recombinant proteins with either a GST-tag or His-tag, respectively (His-RhBax and GST$\mathrm{RhBcl}-2)$, were produced from E. coli BL21. Immunoblotting showed that the GST and GST-RhBcl-2 were successfully pulled down with GST beads and that the GST-RhBcl-2 interacted directly with His-RhBax. GST as a negative control confirmed that the interaction of GSTRhBcl-2 and His-RhBax was specific.

Co-transfection of HEK 293T cells with plasmids containing $R h B c l-2$ and $R h B a x$ genes resulted in co-expression of the proteins. The results also showed that RhBcl-2 and RhBax could interact with each other, but failed to combine without the BH3 domain (Fig. 6b).

\section{RNAi assay of $R h B C l-2$ and RhBax}

To identify the function of $R h B c l-2$ and $R h B a x$, the genes of $R h B c l-2$ and $R h B a x$ were in vivo targets of RNA interference. The RT-qPCR analysis of ticks showed decreased levels of $R h B c l-2$ and $R h B a x$ in $R h B c l-2$ dsRNA and $R h B a x$-dsRNA injected groups compared to luciferase-dsRNA injected controls (Fig. 7b: RhRhBcl-2 RNAi: $t_{(3)}=3.967, P=0.0166$; $R h B a x$ RNAi: $t_{(3)}=4.153$,
$P=0.0142 ; \quad$ Fig. $7 \mathrm{~d}: \quad R h R h B c l-2 \quad$ RNAi: $t_{(3)}=10.80$, $P=0.0004$; RhBax RNAi: $\left.t_{(3)}=3.433, P=0.0265\right)$. There was no significant difference in the attachment rate between the experimental and control groups (Table 1), but females of group $R h B c l-2$ did not reach the full engorgement stage (Fig. 7a) and died on the seventh day to the ninth days. Thus, the engorgement rate and death rates were significantly different compare with control group (Table 1). However, ticks injected with $R h B a x$ dsRNA did not differ from the control groups at any feeding time (Table 1).

TUNEL assays showed that salivary gland interference by $R h B c l-2$ dsRNA increased apoptosis levels, but $R h B a x$ was similar to the control (Fig. 7c, e).

\section{Discussion}

Rhipicephalus haemaphysaloides is a three-host hard tick widely distributed in China. It is a carrier of several human pathogens [37-39]. The salivary glands of female ticks undergo degeneration after engorgement [3]. Apoptosis plays a role in the process while caspase genes and apoptosis-related genes are upregulated [40]. Our study identified and characterized two Bcl-2 family proteins (Bcl-2 and Bax) in R. haemaphysaloides and found them to be involved in salivary gland degeneration. 


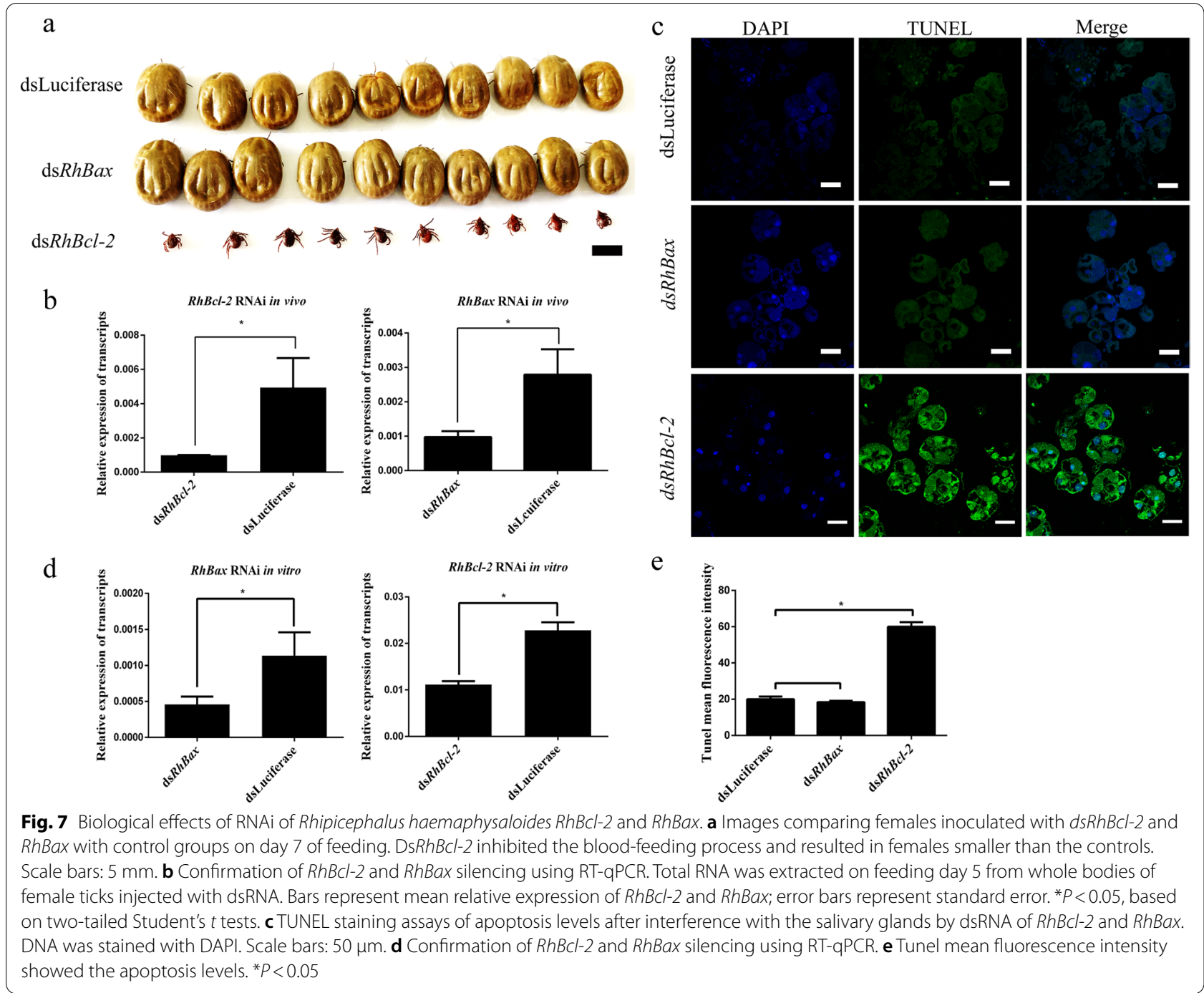

The Bcl-2 family proteins are also found in insects such as Drosophila, Bombyx mori, and Anopheline mosquitoes, and are involved in growth and metamorphosis [24, 41-43]. Ayllon [25] found that Bcl-2 may play a key role in the intrinsic apoptosis of Ixodes scapularis, but other Bcl-2 family proteins and the apoptosis mechanism are unknown. We found that $R h B c l-2$ and $R h B a x$ are involved in salivary gland degeneration in $R$. haemaphysaloides. Sequence analysis demonstrated that $R h B c l$ 2 and RhBax have conserved sequences characteristic of

Table 1 Effect of knocking-down $R h B C l-2$ and RhBax on tick feeding

\begin{tabular}{|c|c|c|c|c|c|}
\hline \multirow[t]{2}{*}{ Parameters } & \multirow{2}{*}{$\begin{array}{l}\text { dsLuciferase } \\
\%(n)\end{array}$} & \multicolumn{2}{|l|}{$\mathrm{ds} R h B C l-2$} & \multicolumn{2}{|l|}{ dsRhBax } \\
\hline & & $\%(n)$ & Chi-square test & $\%(n)$ & Chi-square test \\
\hline Attachment rate at $24 \mathrm{~h}$ & $76.7(60)$ & $85.0(60)$ & $x^{2}=1.345, d f=1, P=0.2462$ & $70.0(60)$ & $x^{2}=0.6818, d f=1, P=0.4090$ \\
\hline Engorgement rate & $73.3(60)$ & $0.0(60)$ & $x^{2}=69.74, d f=1, P<0.0001$ & $61.7(60)$ & $x^{2}=1.8610, d f=1, P=0.1725$ \\
\hline Death rate & $20.0(60)$ & $95.0(60)$ & $x^{2}=69.50, d f=1, P<0.0001$ & $33.3(60)$ & $x^{2}=2.7270, d f=1, P=0.0986$ \\
\hline Egg laying rate & $100.0(30)$ & ND & NA & $96.7(30)$ & $x^{2}=1.0170, d f=1, P=0.3132$ \\
\hline Hatchability rate & $100.0(30)$ & ND & NA & $96.7(30)$ & $x^{2}=1.0170, d f=1, P=0.3132$ \\
\hline
\end{tabular}


$\mathrm{BH}$ domains. The $\mathrm{BH} 3$ domain is a key domain for Bax, Bak, and Bok to promote apoptosis and combine antiapoptosis proteins with proapoptotic proteins [44, 45]. A GST pull-down assay confirmed that RhBcl-2 and RhBax combined with each other. Co-transfection assays also showed that RhBcl-2 and RhBax could interact, but did not combine without the BH3 domain.

Salivary gland degeneration is triggered after the completion of female tick feeding [46]. According to the RTqPCR results, $R h B c l-2$ and $R h B a x$ had a high level of transcription in salivary glands during tick engorgement, as determined by western blot. These findings suggest that the roles of $\mathrm{RhBcl}-2$ and $\mathrm{RhBax}$ are related to salivary glands apoptosis and degeneration.

RNA interference was used to investigate the physiological roles of $R h B c l-2$ and $R h B a x$. TUNEL staining was used to evaluate the rate of DNA fragmentation in degenerated tick salivary glands. By interference with $R h B c l-2$, the TUNEL-positive staining rate increased significantly when compared to the control group. These results demonstrated that $\mathrm{RhBcl}-2$ functions in preventing apoptosis during salivary gland degeneration. $\mathrm{Bax}$ is a proapoptotic protein in the $\mathrm{Bcl}-2$ protein family [47]. However, interference with $R h B a x$ had no significant effect when compared to the control group.

$R h B c l-2$ silencing produced a most significant phenotype alteration in ticks during blood feeding compared to $R h B a x$ and the control groups. After injection with $d s R h B c l-2$, the female ticks were unable to feed and engorge until they died. These data illustrated the importance of $\mathrm{RhBcl}-2$ during blood feeding. Consequently, $R h B c l-2$ functioned to protect cell survival, promote normal organ functioning, and ensure that ticks take in sufficient amount of blood in this stage. The function of the RhBax protein remains unclear.

\section{Conclusions}

In conclusion, two Bcl-2 family molecules were identified in ticks, and the roles of $R h B c l-2$ and RhBax in tick physiology were investigated. These findings enabled advanced studies of tick apoptosis. RhBcl-2 and RhBax, like Bcl-2 and $B a x$ in mammals, work together to regulate apoptosis in tick salivary glands. The knockdown of $\mathrm{RhBcl}-2$ in vivo inhibited blood feeding, indicating that $\mathrm{RhBcl}-2$ has the potential to be used as a tick vaccine protein.

\footnotetext{
Abbreviations

TBPs: Tick-borne pathogens; PCD: Programmed cell death; PcAb: Polyclonal antibodies; RT-qPCR: Reverse transcription quantitative polymerase chain reaction; PBS: Phosphate-buffered saline; TBS: Tris-buffered saline; SDS-PAGE: Sodium dodecyl sulfate polyacrylamide gel electrophoresis; IPTG: Isopropyl $\beta$-D-1-thiogalactopyranoside; DAPI: 4',6'-Diamidino-2-phenylindole; TUNEL: Terminal deoxynucleotidyl transferase dUTP nick-end labeling; $\mathrm{BH}$ : $\mathrm{BCl}-2$ homology.
}

\section{Supplementary Information}

The online version contains supplementary material available at https://doi. org/10.1186/s13071-021-04879-z.

Additional file 1: Table S1. Primers used for quantitative real-time polymerase chain reactions of Rhipicephalus haemaphysaloides $R h B C l-2$ and RhBax genes. Table S2. Primers for Rhipicephalus haemaphysaloides RhBCl-2 and RhBax ORF cloning. Table S3. Primers used for overlap extension (SOE) of recombinant PCR to delete BH domain. Table S4. Primers for RNAi of Rhipicephalus haemaphysaloides RhBCl-2 and RhBax genes.

\section{Acknowledgements}

We thank LetPub (www.letpub.com) for its linguistic assistance during the preparation of this manuscript.

\section{Authors' contributions}

SH conceived the study, performed the statistical analyses, and participated in the dynamic detection of the target genes. SH drafted the manuscript. $Y W$ and $Z X$ participated in the design of the study and the interpretation of the data. YZ, HZ, and JC participated in the experiments on animals. JZ participated in the design of the study and helped to draft the manuscript. All authors read and approved the final manuscript.

\section{Funding}

This work was supported by a grant from the Central Public-interest Scientific Institution Basal Research Fund (No. Y2021 GH01-3) and Strategic International Collaborative Research Project (JPJ008837) promoted by the Ministry of Agriculture, Forestry and Fisheries, Japan.

\section{Availability of data and materials}

All data generated or analysed during this study are included in this published article and its Additional file 1: Tables S1-S4.

\section{Declarations}

\section{Ethics approval and consent to participate}

The treatment of rabbits and mice was approved by the Institutional Animal Care and Use Committee of the Shanghai Veterinary Research Institute (IACUC Approval number: SHVRI-SZ-20190726-02; SHVRI-SZ-20191024-01).

\section{Consent for publication}

Not applicable.

\section{Competing interests}

The authors declare that they have no competing interests.

Received: 20 January 2021 Accepted: 16 July 2021

Published online: 04 August 2021

\section{References}

1. Jongejan F, Uilenberg G. The global importance of ticks. Parasitology. 2004;129:S3-14.

2. Sonenshine DE. Biology of ticks. New York: Oxford University Press; 1991.

3. Simo L, Kazimirova M, Richardson J, Bonnet SI. The essential role of tick salivary glands and saliva in tick feeding and pathogen transmission. Front Cell Infect Microbiol. 2017:7:281.

4. Kazimirova M, Stibraniova I. Tick salivary compounds: their role in modulation of host defences and pathogen transmission. Front Cell Infect Microbiol. 2013;3:43.

5. Francischetti IM, Sa-Nunes A, Mans BJ, Santos IM, Ribeiro JM. The role of saliva in tick feeding. Front Biosci. 2009;14:2051-88.

6. Abdelwahid E, Rolland S, Teng X, Conradt B, Hardwick JM, White K. Mitochondrial involvement in cell death of non-mammalian eukaryotes. Biochim Biophys Acta. 2011;1813:597-607. 
7. Mao H, Kaufman WR. Profile of the ecdysteroid hormone and its receptor in the salivary gland of the adult female tick, Amblyomma hebraeum. Insect Biochem Mol Biol. 1999;29:33-42.

8. L'Amoreaux WJ, Junaid L, Trevidi S. Morphological evidence that salivary gland degeneration in the American dog tick, Dermacentor variabilis (Say), involves programmed cell death. Tissue Cell. 2003;35:95-9.

9. Freitas DR, Rosa RM, Moura DJ, Seitz AL, Colodel EM, Driemeier D, et al. Cell death during preoviposition period in Boophilus microplus tick. Vet Parasitol. 2007:144:321-7.

10. Wang H, Zhang X, Wang X, Zhang B, Wang M, Yang X, et al. Comprehensive analysis of the global protein changes that occur during salivary gland degeneration in female ixodid ticks Haemaphysalis longicornis. Front Physiol. 2018;9:1943.

11. Maghsoudi N, Zakeri Z, Lockshin RA. Programmed cell death and apoptosis-where it came from and where it is going: from Elie Metchnikoff to the control of caspases. Exp Oncol. 2012;34:146-52.

12. Kerr JF, Wyllie AH, Currie AR. Apoptosis: a basic biological phenomenon with wide-ranging implications in tissue kinetics. Br J Cancer. 1972;26:239-57.

13. Serrano-Heras G, Diaz-Maroto I, Castro-Robles B, Carrion B, Perona-Moratalla AB, Gracia J, et al. Isolation and quantification of blood apoptotic bodies, a non-invasive tool to evaluate apoptosis in patients with ischemic stroke and neurodegenerative diseases. Biol Proc Online. 2020;22:17.

14. Shi Y. Mechanical aspects of apoptosome assembly. Curr Opin Cell Biol. 2006:18:677-84.

15. Yin F, Zhou H, Fang Y, Li C, He Y, Yu L, et al. Astragaloside IV alleviates ischemia reperfusion-induced apoptosis by inhibiting the activation of key factors in death receptor pathway and mitochondrial pathway. J Ethnopharmacol. 2020;248:112319.

16. Santos LC, Vogel R, Chipuk JE, Birtwistle MR, Stolovitzky G, Meyer P. Mitochondrial origins of fractional control in regulated cell death. Nat Commun. 2019;10:1313.

17. Adams JM, Cory S. Bcl-2-regulated apoptosis: mechanism and therapeutic potential. Curr Opin Immunol. 2007;19:488-96.

18. Tsujimoto Y, Cossman J, Jaffe E, Croce CM. Involvement of the bcl-2 gene in human follicular lymphoma. Science. 1985;228:1440-3.

19. Hartman ML, Czyz M. BCL-w: apoptotic and non-apoptotic role in health and disease. Cell Death Dis. 2020;11:260.

20. Gross A, Jockel J, Wei MC, Korsmeyer SJ. Enforced dimerization of BAX results in its translocation, mitochondrial dysfunction and apoptosis. Embo J. 1998; 17:3878-85.

21. Minn AJ, Swain RE, Ma A, Thompson CB. Recent progress on the regulation of apoptosis by Bcl-2 family members. Adv Immunol. 1998;70:245-79.

22. Strasser $\mathrm{A}$. The role of $\mathrm{BH} 3$-only proteins in the immune system. Nat Rev Immunol. 2005:5:189-200.

23. Deng J, Carlson N, Takeyama K, Dal Cin P, Shipp M, Letai A. BH3 profiling identifies three distinct classes of apoptotic blocks to predict response to ABT-737 and conventional chemotherapeutic agents. Cancer Cell. 2007;12:171-85

24. Igaki T, Miura M. Role of Bcl-2 family members in invertebrates. Biochim Biophys Acta. 2004;1644:73-81.

25. Ayllon N, Villar M, Galindo RC, Kocan KM, Sima R, Lopez JA, et al. Systems biology of tissue-specific response to Anaplasma phagocytophilum reveals differentiated apoptosis in the tick vector Ixodes scapularis. PLoS Genet. 2015;11:e1005120

26. Zhou J, Gong H, Zhou Y, Xuan X, Fujisaki K. Identification of a glycine-rich protein from the tick Rhipicephalus haemaphysaloides and evaluation of its vaccine potential against tick feeding. Parasitol Res. 2006;100:77-84.

27. Yu X, Gong H, Zhou Y, Zhang H, Cao J, Zhou J. Differential sialotranscriptomes of unfed and fed Rhipicephalus haemaphysaloides, with particular regard to differentially expressed genes of cysteine proteases. Parasit Vectors. 2015;8:597

28. Wang Y, Hu S, Tuerdi M, Yu X, Zhang H, Zhou Y, et al. Initiator and executioner caspases in salivary gland apoptosis of Rhipicephalus haemaphysaloides. Parasit Vectors. 2020;13:288.

29. Cruz LM, Trefflich S, Weiss VA, Castro MAA. Protein function prediction. Methods Mol Biol. 2017:1654:55-75.

30. Artimo P, Jonnalagedda M, Arnold K, Baratin D, Csardi G, de Castro E, et al. ExPASy: SIB bioinformatics resource portal. Nucleic Acids Res. 2012:40:W597-603

31. Nijhof AM, Balk JA, Postigo M, Jongejan F. Selection of reference genes for quantitative RT-PCR studies in Rhipicephalus (Boophilus) microplus and
Rhipicephalus appendiculatus ticks and determination of the expression profile of Bm86. BMC Mol Biol. 2009;10:112.

32. Livak KJ, Schmittgen TD. Analysis of relative gene expression data using real-time quantitative PCR and the 2(-Delta Delta $C(T)$ ) Method. Methods. 2001;25:402-8.

33. Ginzinger DG. Gene quantification using real-time quantitative PCR: an emerging technology hits the mainstream. Exp Hematol. 2002;30:503-12.

34. Kim HS, Smithies O. Recombinant fragment assay for gene targetting based on the polymerase chain reaction. Nucleic Acids Res. 1988;16:8887-903.

35. Greenfield EA, DeCaprio J, Brahmandam M. Making weak antigens strong: cross-linking peptides to KLH with maleimide. Cold Spring Harb Protoc. 2018. https://doi.org/10.1101/pdb.prot100016.

36. Grabowski JM, Tsetsarkin KA, Long D, Scott DP, Rosenke R, Schwan TG, et al. Flavivirus infection of ixodes scapularis (black-legged tick) ex vivo organotypic cultures and applications for disease control. MBio. 2017;8:e01255-17.

37. Chen Z, Yang X, Bu F, Yang X, Yang X, Liu J. Ticks (acari: ixodoidea: argasidae, ixodidae) of China. Exp Appl Acarol. 2010;51:393-404.

38. Yu Z, Wang H, Wang T, Sun W, Yang X, Liu J. Tick-borne pathogens and the vector potential of ticks in China. Parasit Vectors. 2015;8:24.

39. Zhang J, Liu Q, Wang D, Li W, Beugnet F, Zhou J. Epidemiological survey of ticks and tick-borne pathogens in pet dogs in south-eastern China. Parasite. 2017;24:35.

40. Yu X, Zhou Y, Cao J, Zhang H, Gong H, Zhou J. Caspase-1 participates in apoptosis of salivary glands in Rhipicephalus haemaphysaloides. Parasit Vectors. 2017:10:225

41. Brachmann CB, Jassim OW, Wachsmuth BD, Cagan RL. The Drosophila bcl-2 family member $d B o r g-1$ functions in the apoptotic response to UV-irradiation. Curr Biol. 2000;10:547-50.

42. Colussi PA, Quinn LM, Huang DC, Coombe M, Read SH, Richardson H, et al. Debcl, a proapoptotic BCl-2 homologue, is a component of the Drosophila melanogaster cell death machinery. J Cell Biol. 2000;148:703-14.

43. Igaki T, Kanuka H, Inohara N, Sawamoto K, Nunez G, Okano H, et al. Drob-1, a Drosophila member of the BCl-2/CED-9 family that promotes cell death. Proc Natl Acad Sci USA. 2000;97:662-7.

44. Chou JJ, Li H, Salvesen GS, Yuan J, Wagner G. Solution structure of BID, an intracellular amplifier of apoptotic signaling. Cell. 1999;96:615-24.

45. McDonnell JM, Fushman D, Milliman CL, Korsmeyer SJ, Cowburn D. Solution structure of the proapoptotic molecule BID: a structural basis for apoptotic agonists and antagonists. Cell. 1999;96:625-34.

46. Scopinho Furquim KC, Bechara GH, Camargo Mathias MI. Death by apoptosis in salivary glands of females of the tick Rhipicephalus sanguineus (Latreille, 1806) (Acari: Ixodidae). Exp Parasitol. 2008;1 19:152-63.

47. Oltvai ZN, Milliman CL, Korsmeyer SJ. BCl-2 heterodimerizes in vivo with a conserved homolog, Bax, that accelerates programmed cell death. Cell. 1993;74:609-19.

\section{Publisher's Note}

Springer Nature remains neutral with regard to jurisdictional claims in published maps and institutional affiliations.

Ready to submit your research? Choose BMC and benefit from

- fast, convenient online submission

- thorough peer review by experienced researchers in your field

- rapid publication on acceptance

- support for research data, including large and complex data types

- gold Open Access which fosters wider collaboration and increased citations

- maximum visibility for your research: over 100M website views per year

At BMC, research is always in progress.

Learn more biomedcentral.com/submissions 